XI. Methyl Alcohol $(M=32)$.

\begin{tabular}{|c|c|c|}
\hline g. per 100 & $s^{3}$ & $M$ \\
\hline 0.5657 & I. 149 & 33.2 \\
\hline I. 134 & 2.225 & 34.4 \\
\hline I. 857 & 3.575 & 35.0 \\
\hline 2.304 & 4.320 & 35.9 \\
\hline \multicolumn{3}{|c|}{$\cos o t(M=92)}$. \\
\hline 0.7927 & 0.607 & 88.0 \\
\hline 2.062 & 1.702 & 81.7 \\
\hline $3 \cdot 394$ & 3.288 & 69.6 \\
\hline \multicolumn{3}{|c|}{ ctic Acid $(M=60)$. } \\
\hline 0.5902 & 0.640 & 62.2 \\
\hline 1.247 & I. 343 & 62.6 \\
\hline 2.593 & 2.6 .41 & 66.0 \\
\hline \multicolumn{3}{|c|}{ rea $(M=60)$. } \\
\hline 1.672 & $1.6,6$ & 67.2 \\
\hline 2.332 & $2.35^{6}$ & 66.7 \\
\hline 3.692 & 3.574 & 69.6 \\
\hline
\end{tabular}

It will be observed that the general trend of the molecular weights. determined here is similar to that of those determined in $\mathrm{CaCl}_{2}, 6 \mathrm{H}_{2} \mathrm{O}$, $\mathrm{LiNO} \cdot 3 \mathrm{H}_{2} \mathrm{O}$, and $\mathrm{Na}_{2} \mathrm{CrO}_{4} \cdot \mathrm{IOH}_{2} \mathrm{O}$, except that in the cases of ethyl alcohol and glycerol in $\mathrm{Mn}\left(\mathrm{NO}_{3}\right)_{2} \cdot 3 \mathrm{H}_{2} \mathrm{O}$ (Tables $X I V$ and $X V I$ ), and formamide in $\mathrm{Zn}\left(\mathrm{NO}_{3}\right)_{2} \cdot 3 \mathrm{H}_{2} \mathrm{O}$ (Table $X I$ ) the molecular weights show a decided decrease with increased concentration. As soon as sufficient data of this sort are at hand, a quantitative study of the thermal relations of these solutions will be made, in order, if possible, to test the effect of the heat of dilution upon the nolecular weight, as calculated by the freezing point law, the possible effect of which has already been sketched by Morgan and Benson ${ }^{1}$.

\title{
Summary.
}

The results of this work may be summarized as follows:

I. The freezing point constants of molten $\mathrm{Ca}\left(\mathrm{NO}_{3}\right)_{2} \cdot 4 \mathrm{H}_{2} \mathrm{O}, \mathrm{Zn}\left(\mathrm{NO}_{3}\right)_{2^{4}}$ ${ }_{3} \mathrm{H}_{2} \mathrm{O}$, and $\mathrm{Mn}\left(\mathrm{NO}_{3}\right)_{2} \cdot 3 \mathrm{H}_{2} \mathrm{O}$ are respectively: $59^{\circ} .4\left(\mathrm{~F} . \mathrm{P} .=42^{\circ} .3 \mathrm{I}\right)$; $5^{\circ} .6\left(\right.$ F. P. $\left.=44^{\circ} .07\right)$, and $67^{\circ} .4\left(\right.$ F. P. $\left.=34^{\circ} .81\right)$.

2. The heats of fusion for $\mathrm{I} g$. each of $\mathrm{Zn}\left(\mathrm{NO}_{3}\right)_{2} \cdot 3 \mathrm{H}_{2} \mathrm{O}$ and $\mathrm{Mn}\left(\mathrm{NO}_{3}\right)_{2} \cdot 3 \mathrm{H}_{2} \mathrm{O}$, as calculated from the experimentally determined values of $\mathrm{K}$, and the relation $w=\frac{0.02 \mathrm{~T}^{2}}{\mathrm{~K}}$, are respectively 34.3 gram-calories at freezing point, $44^{\circ} .07$, and 28.09 gram-calories at the freezing point, $34 \cdot{ }^{\circ} 81$.

LABORATORY OF PHYSICAL CHEMISTRY, August, I907.

[CONTRIBUTION FROM THE HAVEMEYER LABORATORIES OF COLUMBIA [NIVERSITY, No. I43].

\section{PLATINUM RESISTANCE FURNACE FOR MELTING POINTS AND COMBUSTIONS.}

The small furnace here described was the outcome of some work in ${ }^{1}$ Loc cit. 

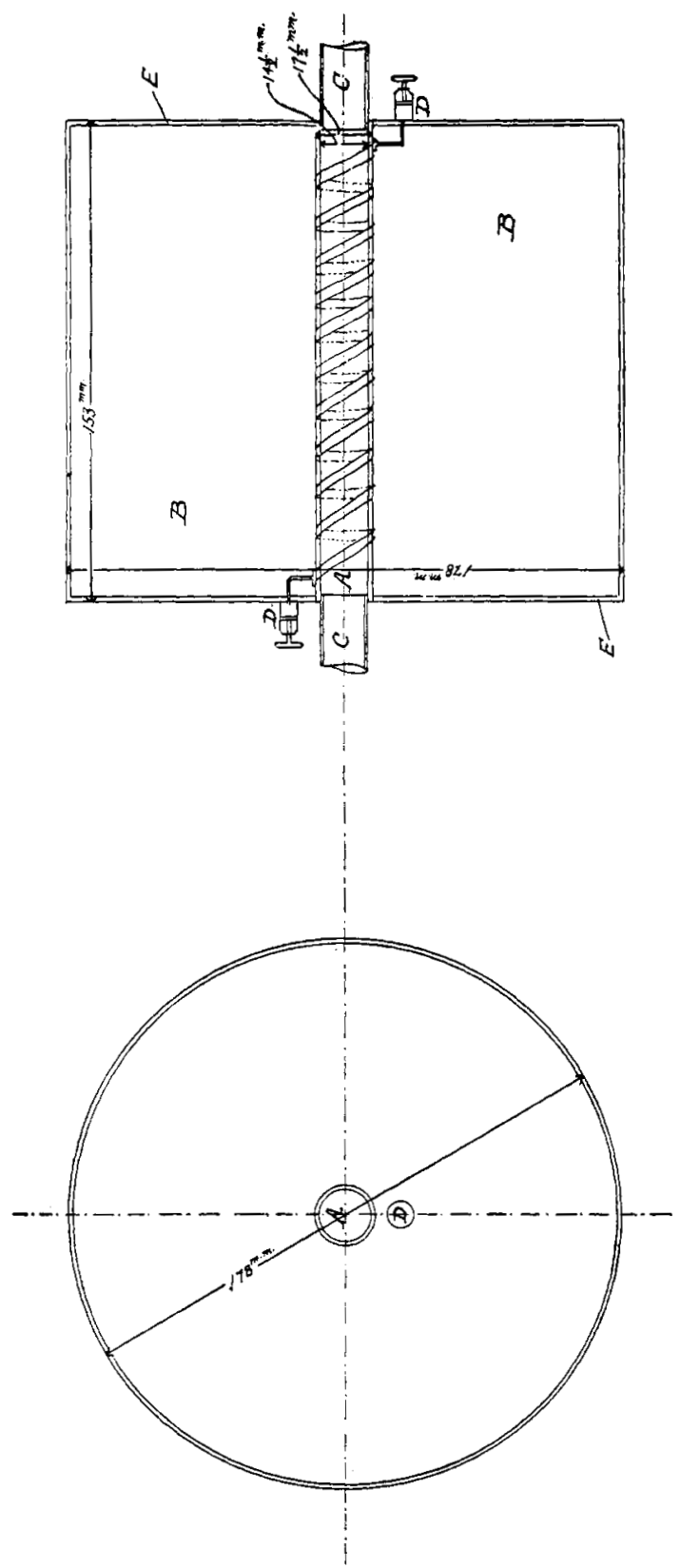

connection with the combustion of carbides in chlorine, and was found very useful for combustions requiring high temperatures. It subsequently 
proved applicable to melting point determinations up to $\mathrm{I} 200^{\circ}$, such as those of copper mattes, etc.

The furnace consists of a quartz tube $A$, wound with platinum tape. The figure gives the side and end elevations. With the dimensions as shown, the tape was $51 \mathrm{~cm}$. long, $6 \mathrm{~mm}$. wide, and $0.06 \mathrm{~mm}$. thick. The ends of the tape rvere welded to short pieces of No. I 2 S. W. G. platinum wire to serve as leads, and the tape was held in position by asbestos cord binding.

The containing walls $E$, are of sheet asbestos, which is easily made to the shape shown, two disks for the ends being cemented to the cylinder. All the joints were cemented with "asbestos cement", which holds the pieces very firmly and takes but a few minutes to set.

The wires leading in were connected to suitable binding posts $D$, and the open space $B$, between the quart $z$ tube and containing walls was filled with infusorial earth. At the temperatures possible with this furnace, infusorial earth makes the best heat insulating material, and its use makes it possible to construct a relatively large furnace of light weight.

The construction would have been better if a longer quartz tube had been used, but at the time that it was made this was impossible to procure, and it necessitated joining in Jena glass tubes $C$, for use in combustion work. The glass tubes were easily joined to the quartz by the same cement.

For use in melting point determinations the glass tubes are removed, the furnace being set up on one end and a plug of asbestos placed in the tube making a seat for a small graphite crucible which rests on the middle portion of the tube.

The material is then placed in the crucible together with the junction of a thermo-couple, and the material melted by raising the current gradually.

The following gives the energy required for higher temperatures for melting point determinations:

$\begin{array}{cc}\text { Hinutes } & \text { Amperes } \\ 4 & 30 \\ 6 & 25 \\ 7 & : \\ 12 & \because 6 \\ 15 & " . \\ 23 & \text { ". } \\ 45 & \end{array}$

\begin{tabular}{|c|c|}
\hline Volts & 'Temperature \\
\hline I 4 & $\mathrm{I} 280^{\circ}$ \\
\hline I 1.8 & I 310 \\
\hline$"$ & I 320 \\
\hline '. & 1190 \\
\hline & 1170 \\
\hline & $\operatorname{II} 7^{\circ}$ \\
\hline & I I 80 \\
\hline
\end{tabular}

For combustions, a temperature of $800^{\circ}$ is obtained with i 8 amperes, the drop across the furnace being 9 volts.

Higher temperature for melting point determinations are obtained with 25 amperes at II volts, which gives a temperature of $I 180^{\circ}$ and with 30 amperes at 14 volts a temperature of $1300^{\circ}$ may be reached. 